\title{
The Use of Morabara Game to Concretise the Teaching of the Mathematical Content
}

\author{
Mr Moloi, Tshele J \\ University of the Free State-QwaQwa Campus \\ Email: moloijt@qwa.ufs.ac.za
}

Doi:10.5901/mjss.2014.v5n27p585

\begin{abstract}
This paper uses Morabara as an example of indigenous game to teach mathematical content in a simplified version. Morabara game helps to teach mathematical contents in an interesting way. This study is framed within the community cultural wealth theory, which validates the marginalised knowledge possessed by the subaltern learners. This kind of teaching of mathematics allows various partners such as teachers, parents, other community members and leaders to work collectively. This concurs with what De Corte( 2000) contends about learning as a partnership between learners, teachers, parents, employers, and the community members working together. Thus, the study used Participatory Action Research (PAR) as the method of generating data. As Eruera,(2010) argues that PAR empowers the research participants and ensures that the voices of marginalised people are included and contribute to the teaching and learning of mathematical concepts. The paper employ the Critical discourse Analysis (CDA) to analyse the generated data. CDA is used to get the deeper meaning of the spoken words/text made at both discursive practice and social structures (Mahlomaholo,2012).
\end{abstract}

Keywords: morabaraba game, mathematical content, marginalised knowledge

\section{Introduction and Background}

\subsection{Content is too abstract in the teaching of problem solving skills}

According to Chilisa (2012) and Lynn (2006) it is clear that the cultural wealth that learners brought from home is relegated to the margins of the classrooms in the learning mathematics. The navigational capital as one element of community cultural wealth theory (Yosso,2005) affords learners an opportunity to understand their environmental background and contexts easily. In the same vein, the manner in which mathematical concepts are taught in school, teachers tend to ignore the cultural background and the context of learners. As the result learners do not comprehend the presented mathematical content (Anthony, 2009).

In addition, the Department of Education's (DoE)(2003) National Curriculum Statement Policy states that in order to convey precise meanings to the teaching of mathematics its content should not exist in isolation to the context of the world where the learner finds himself or herself in. Campbell (2006) cited Keller (2000); Graven \& Schafer (2013) added that it is important to affirm what learners know from their home environment, so that it becomes easy for them to acquire new mathematical skills to what already exists in their knowledge schema. This will assist learners of the subaltern community to get access to mathematics with regard to problem solving skills

Similarly, DoE (2003) through its outcomes-based education (OBE) principles and Su, Yu-Law, Choi, Lee, Choi \& McAninch (2013) assert that prior learning needs to be recognised in the teaching of mathematical skills. This helps to integrate the new knowledge on mathematics skills to the cultural background knowledge on problem solving skills gained through interaction with the society. New knowledge taught in class to learners is easily concretised. In such instances the teaching and learning of mathematical content and skills do not rely solely on prescribed textbooks, but it is diversified on various teaching and learning materials, which include hands-on- activities. Such activities stimulate the mental thinking of the learners to contextualise knowledge and retain the gained information for long-term duration (Tulving (1985) quoted by Campbell (2006). The gained knowledge on mathematical concepts is applied to unfamiliar problem solving skills which learners are confronted with in an authentic environment.

Furthermore, Department of Basic Education (2011) and Grinstein \& Lipsay, (2001) contend that the teaching of mathematics needs to reflect the humanistic dimension, which is often limited in the content of problem solving. In most cases, teachers focus on content in an abstract way such that learners do not have access to the mathematical content. For instances, the teaching of ascending and descending orders in mathematics is only taught in the context of numbers, no authentic situation which relate to their daily life of learners is referred to. Hence, the paper argues that the use of 
morabaraba can significantly assist learners in getting deeper understanding on mathematical content.

\section{The Lens}

The paper is grounded by community cultural wealth theory, focussing on the wealth of knowledge which the marginalised groups possess. Such knowledge is key to concretise the teaching and learning of mathematics.

Lynn (2004) and Yosso $(2002 ; 2005)$ argue that community cultural wealth focuses on and learns from the array of cultural knowledge, skills, abilities and contacts possessed by socially marginalised groups that often go unrecognised and unacknowledged. In this paper, the use of morabaraba game as an example of indigenous game is a way of validating and recognising the cultural practices of various communities.

On the other hand, Leonard (2008) emphasised that mathematical problem-solving, like all other forms of knowledge, is situated within a cultural context. Consequently, counting can be conceptually understood as both a knowledge form and a cultural practice that enables learners to organise their world. Engaging cultural norms in the classroom is at the heart of teaching cultural relevance.

Finally, the community cultural knowledge theory maintains that all participants in the research can play a vital role in the teaching and learning of mathematics. The classroom participants, among others can include learners, parents, teachers from mathematics and other social sciences subjects, community members, and education officials at district or provincial levels

\section{Methodology and Design}

The paper utilised participatory action research (PAR), which recognises community members as experts and is empowering for communities who are enabled to find their own solutions to local issues (Moana, 2010). In the context of this paper, the researcher and participants were empowered in using morabaraba as an indigenous game to solve problems and identify mathematical concepts embedded in it. The marginalised capital was explored to understand mathematical concepts by using cultural games, particularly morabaraba. As Yosso (2005) argues, there is much cultural capital in the communities which is not being adequately utilised.

The researcher assembled a team of grade 10 learners in one school located in the rural area of QwaQwa, one deputy principal, one head of department (HOD), three grade 10 Mathematics teachers, two life orientation teachers, two district officials from the Department of Basic Education (DBE), one in the sports section and two Mathematics subject advisors, ten parents with knowledge of various indigenous games and two members of the royal family who are the custodians of indigenous games, and a lecturer in the school of Mathematics, Science and Technology Education from the university.

The use of morabaraba to concretise the teaching of mathematical concepts was implemented in one school in the rural area of QwaQwa, in Thabo Mofutsanyana Education District. For confidentiality and anonymity the school and participants were given pseudonyms. In stimulating the debate the Free Attitude Interview (FAI) (Buskens, 2011) was followed, so as to ensure that participants were central to the study and their voices heard, rather than being seen as objects to be manipulated and controlled in a setting removed from the real world of their lived experiences (McGregor \& Murnane, 2008 Stinson \& Bullock, 2012).

\section{Findings, Discussions and Conclusions}

\subsection{Meaningful subject-matter in the teaching of mathematical concepts}

According to Lynn (2004) and Yosso(2002) the teaching of mathematics should draw on the strengths of learners nurtured from homes. The subject matter to be presented in mathematics class will then make sense to learners. They argue that there is no deficit in the learners' language, culture and their lived experiences. So it is important for the teachers do consider these capital wealths for the teaching and learning of mathematics to be simplified and be meaningful. Among others, the lived experiences of learners can include storytelling, indigenous games, and family histories but not limited these few mentioned.

However, DoE (2003);Haylock(2010) and Van de Walle, Karp \& Bay-Williams (2010) contend that the teaching of mathematics must be learner -centred for learners to have access into mathematical content. This supports the ontological and epistemological stances of the community cultural wealth theory that knowledge and nature of reality do not reside within one powerful individual. But there are multiple realities shaped by the set of multiple connections that 
human beings have with the environment and nature of knowledge is subjective(Chilisa \& Ntseane,2010). Rather than the teacher taking the centre stage, trying to explain everything for learners. This relates to what Van de Walle et al (2010) quoted Schifter \& Fosnot(1993) that no matter how lucidly and patiently teachers explain the subject -matter to their learners, the truth is, they cannot understand for their learners. If the teacher explains everything to learners, it's like their potentialities are oppressed and marginalised. Hence, in the research the team members used the morabaraba to concretise the teaching of mathematics, to allow learners, teachers, and parents to unearth the mathematical content contained within morabaraba game as an example of indigenous game.

\subsection{Lesson preparation}

For learners to gain meaningful understanding in the mathematical content, it is essential that in the lesson preparations they are included too. Such collaborative lesson preparation create learning environment that engage learners, while providing deep learning opportunities (Hamalainen, Manninen,Jarvel, 2006;Jorgensen \& Lowrie,2013). This is in agreement with what Muijis and Reynolds (2011) argue that it becomes easy for the teacher to teach from learners' perspective, if learners and parents(Van de Walle et al,2010) are involved at the preparation stage. This helps to avoid bringing in unfamiliar context for learners in the learning of mathematics. Also, contribute in making mathematics to appear abstract for the learners.

In addition, Lynn (2004) cited Delgado Bernal (1998, 2002); Solórzano \& Yosso (2002) contends that the lesson preparation involving learners assist in harmonising the relationship between home environment and mathematical knowledge taught in the classrooms.

In line with above trends, the paper has adopted the approach where various stakeholders took part in crafting the lesson preparation. The team in the research comprised of mathematics teachers, Life Orientation teachers, HOD: Mathematical Sciences, Deputy Principal, Traditional leaders, Parents, district departmental officials (mathematics subject advisor and Officials from Sports section) and mathematics grade 10 learners.

In making sure that the background of the learners is taken into consideration when teaching mathematics (Graven, 2003). The team came up with the plan of action (see Table 1 below) that guided them to roll out the teaching of mathematical content and skills using morabaraba game.

\section{Table 1: Plan of Action}

\begin{tabular}{|c|c|c|c|c|}
\hline Activities & Person responsible & Monitoring & Evaluation & Timeframe \\
\hline $\begin{array}{c}\text { Phase 1: Playing of } \\
\text { Morabaraba game }\end{array}$ & $\begin{array}{c}\text { Two pairs of learners and } \\
\text { parents volunteered to play the } \\
\text { game }\end{array}$ & $\begin{array}{c}\text { Mathematics Teachers } \\
\text { and other research } \\
\text { participants }\end{array}$ & $\begin{array}{c}\text { Observation sheet used to record } \\
\text { observations }\end{array}$ & $\begin{array}{c}45 \\
\text { minutes }\end{array}$ \\
\hline $\begin{array}{c}\text { Phase 2: Reflection on } \\
\text { the lesson learnt from } \\
\text { playing the game }\end{array}$ & $\begin{array}{c}\text { Grade 10 class and the focus } \\
\text { group }\end{array}$ & $\begin{array}{c}\text { Mathematics Teachers } \\
\text { and other research } \\
\text { participants }\end{array}$ & $\begin{array}{c}\text { Discussion on mathematics } \\
\text { concepts/skills/knowledge identified } \\
\text { from the game }\end{array}$ & $\begin{array}{c}30 \\
\text { minutes }\end{array}$ \\
\hline $\begin{array}{c}\text { Phase 3: Presentation of } \\
\text { the lesson: }\end{array}$ & $\begin{array}{c}\text { Subject teachers: The } \\
\text { Researcher or the grade 10 } \\
\text { teachers or mathematics } \\
\text { subject advisor }\end{array}$ & $\begin{array}{c}\text { Mathematics Teachers } \\
\text { and other research } \\
\text { participants }\end{array}$ & $\begin{array}{c}\text { Lesson plan is crafted based on the } \\
\text { identified mathematical concept }\end{array}$ & $\begin{array}{c}60 \\
\text { minutes }\end{array}$ \\
\hline $\begin{array}{c}\text { Phase 4: reflection on } \\
\text { the lesson presented }\end{array}$ & $\begin{array}{c}\text { Grade 10 learners and focus } \\
\text { group participants }\end{array}$ & $\begin{array}{c}\text { Mathematics Teachers } \\
\text { and other research } \\
\text { participants }\end{array}$ & $\begin{array}{c}\text { Comments and recommendations from } \\
\text { other research participants }\end{array}$ & $\begin{array}{c}30 \\
\text { minutes }\end{array}$ \\
\hline $\begin{array}{c}\text { Assessment of the } \\
\text { lesson }\end{array}$ & $\begin{array}{c}\text { Teacher assessment, peer- } \\
\text { assessment, and parent } \\
\text { assessment }\end{array}$ & $\begin{array}{c}\text { The presenter and } \\
\text { other subject experts }\end{array}$ & $\begin{array}{c}\text { Give feedback on activities done } \\
\text { during class, after class or at home }\end{array}$ & $\begin{array}{c}45 \\
\text { minutes }\end{array}$ \\
\hline
\end{tabular}

The activities showed how morabaraba as an indigenous game was played in teaching of mathematical content areas such as number patterns, functions, geometry etc. This approach of planning assisted the group to bring the learners' home background or real life situations into the classroom. This helped to concretise the mathematical content and skills to be easily understood by learners. The activity column is done in five phases or stages, where at times these stages overlapped. For each phase there were proper collaborative planning beforehand to ensure that lesson outcomes are reached as anticipated. For instances if the team has decided to play morabaraba, the people or small team to lead in playing the game must be organised in time. Tools, instruments and all resources that will be needed were put together 
by the team. The worksheets and observation sheets (refer to Fig. 1) to be used must be ready. All team members need to be clear of the roles they have to play. As the lesson presentation is interactive no fixed roles are assigned to members. Although there is one person who will lead the discussions or deliberations, every members is free to interject at any given point. The dominant roles played by teachers, experts, and parents are facilitating the small group formed by learners. In every small group of learners there is a teacher and /or parent, and or mathematics subject advisor etc. They are there to monitor learners' progress and to do coaching, scaffolding, modelling, reflection only when it is necessary to do so.

During the play of morabaraba it must be very clear who will lead in the play and other team members are expected use observation sheet (Fig.1 below) as they observe. This helps members to capture important issues that will be discussed during reflection session.

After lesson preparation was smoothly handled by the team, then phase 1 and phase 2 as reflected in the plan of Action were executed. For instance, Picture 1 below, shows that learners and parents teams were playing morabaraba, while other members of the team (spectators) were using observation sheet(Fig. 1 below) to write their observations. The observations ranged from the structural nature of the game and actual playing of the game, whereby team members (learners in particular) have to mention any mathematical concepts embedded within the morabaraba game played at that time. This helped the teacher to teach from learners' perspective, and also allowing learners to discover and reflect on realistic experiences.

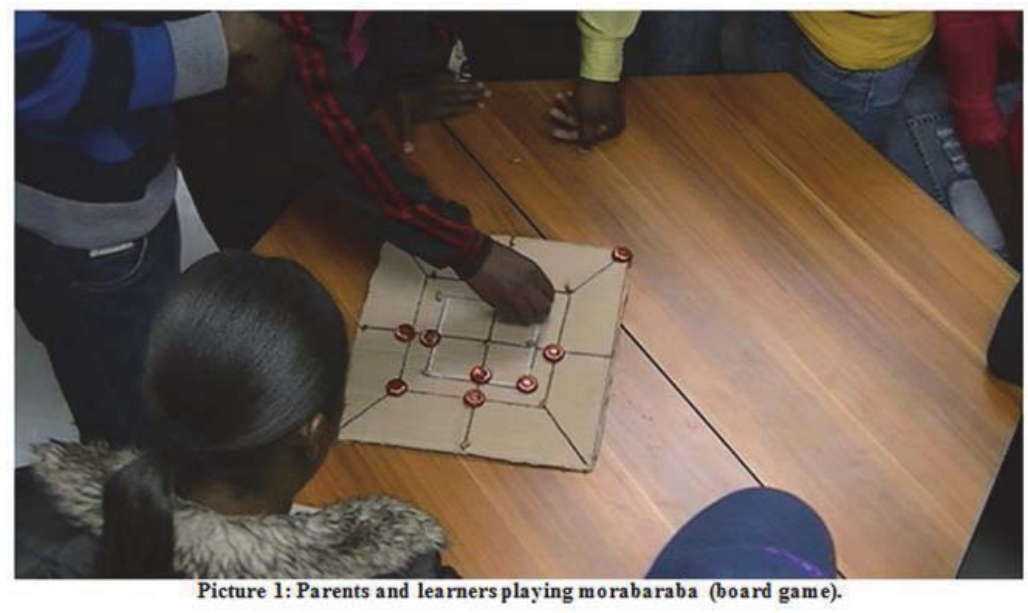

In phase 2, referred to in Table 1 as the reflections on the lesson learnt from playing of morabaraba, one group in class reported as follows, the report back is captured in the observation sheet(refer to Fig. 1 below), which they have to address the main headings such as the structural nature of the game and the actual playing of the game, under each heading they needed to specify any mathematical concepts, skills or knowledge observed, and mention any information they deem it fit to share to the whole class.

Group 1: rona ha re shebile straturale neitjha sa morabaraba, re bona rektengele e nyane, ho latele e kgolwanyane, e kgolo,(lebella Fig.2 below) ) jwalo-jwalo. rektengele tseo di entswe ka dilaene. Ha papadi e bapalwa re bona tsena, re beha dikgomo tsa rona ka ho fapanyetsana, o lokela ho nahana ka kelo hloko pele o beha kgomo ya hao, hore o tsebe 0 hlola enwa wa direng. O menahana mokgwa wa ho hlola papadi ena(Translated in English: as we view the structural nature morabaraba (board game), we see rectangle of various sizes, the big one, the bigger one, and the biggest one (see Fig.2 below) These rectangles are made out of lines .On the actual playing of the game, these are apparent; we play by giving chance to each opponent to place his/her token cow on the board, you have to think strategically before you place the token cow on the board, so as to maximise chances of winning the game, and also anticipating the movement that the opponent might take) 


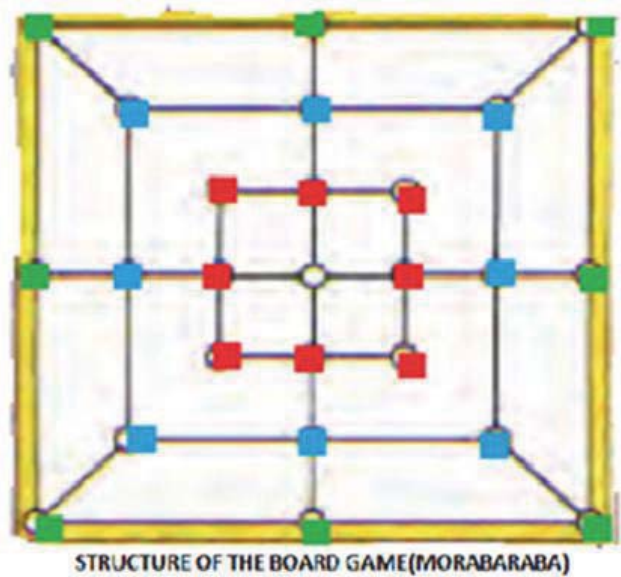

Fig. 2

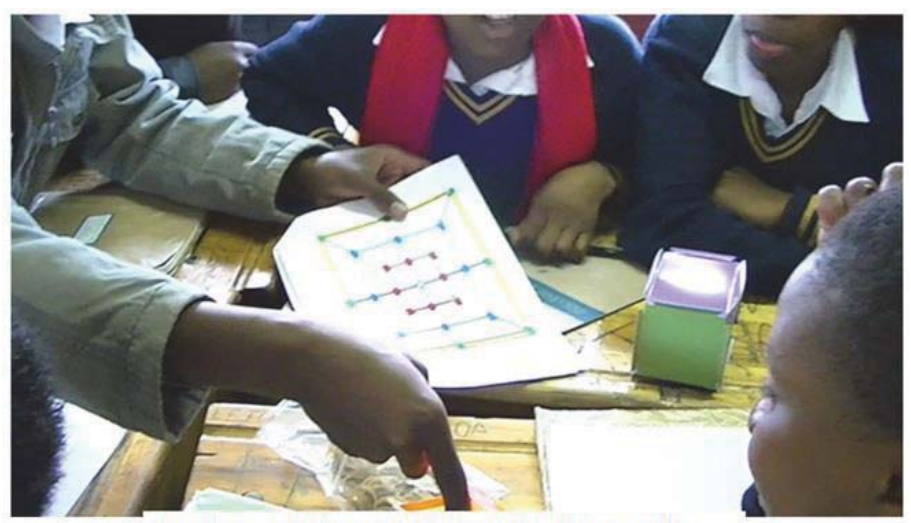

PICTURE 2: GROUP 1 RE PORTING BACK AFTER THEIR

DISCUSSTONS

OBSERVATION SHEET

Activity: Morabaraba game

STRUCTURAL NATURE OF THE GAME

Mention any mathematical concepts/skills/knowledge that you observe

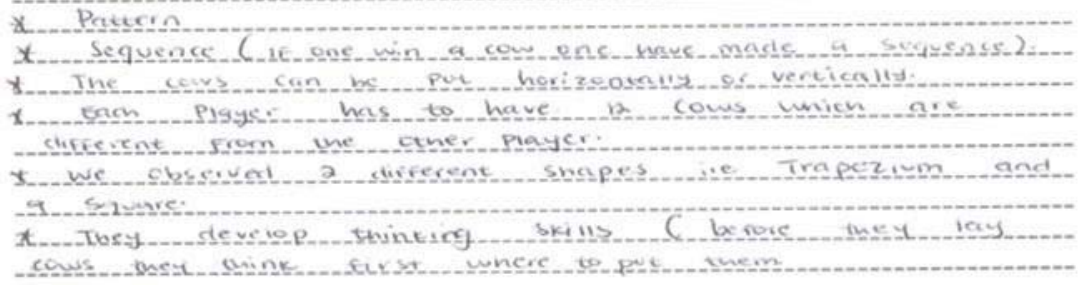

Any other observations you want to mention:

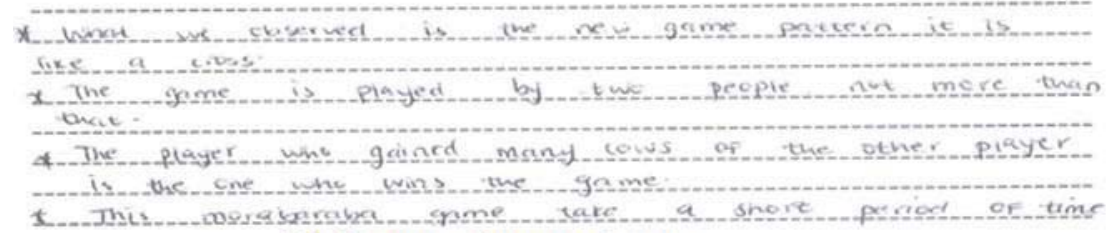

Fig. 1: responses from some learners

In the extract above, it shows that learners are able to interact freely among themselves. The teacher has given them 
freedom to think freely of mathematical content and skills embedded within morabaraba (board game). Then the teacher was able to design the lesson plan which included the mathematical content and skills mentioned by learners. In this way the lesson plan was flexible as one plan according to the prior knowledge of learners.

Thus, the learners are empowered to decide on the content to be taught; as such this content is infused with the context they are familiar with. Fig. 1 above, showed the mathematics concepts or content mentioned by learners. As the result the teacher packaged the content raised by learners into the class activities to be presented. For example in the extract above, and Fig 1 above, learners mentioned patterns, then the teachers elaborated the concepts by showing that with morabaraba there are patterns like ascending or descending patterns. In this way learners are given hope that the mathematical content they mentioned such as sequences, rectangles, lines, chances of winning the game fall within the parameters of their syllabus(i.e. contained in Curriculum and Assessment Policy Statement (CAPS)). The playing of morabaraba has resuscitated these concepts which they know from their home experiences. As the teacher gets into details of the concepts it's easy for learners to relate new knowledge to what they previously know.

As learners or teams members interacted with their various groups to share their reflections, they demonstrated that they possess social capital. The navigational skills is illustrated as they make analysis and interpretations of the mathematical concepts or skills they observed from the playing of the game.

As the extract indicates '.... we see rectangle of various sizes, the big one, the bigger one, and the biggest one.....'), that what they conceptualised was true, they saw patterns or sequences of rectangular shapes, which differ according to sizes. The powerfulness of linguistic capital enabled learners to use words such big, bigger and biggest to describe the pattern of rectangles they observed. The ability of linguistic skill assisted learners to understand mathematical concepts such ascending order and descending order, and concentric geometric patterns. These are the mathematical content (algebraic expressions, equations, number patterns and geometry and analytical geometry) which are featured in grade 10 mathematics Curriculum and Assessment Policy Statement (CAPS). Furthermore, they capitalised on the linguistic capital to describe the shapes properly. This revealed how the geometric figures are arranged in a particular sequence and also explaining how these geometric figures relate. Mathematically, it shows that they realised that these geometric figures [see Fig.2] are ordered in concentric way.

In addition, the extract shows that learners were able to perform high cognitive skills of analysing and synthesis skills. The teaching and learning of mathematics have to teach such skills and assess them. From the cultural wealth theory, learners already possessed these rich skills; it is then the responsibility of the teachers and community members at large to nurture and develop these skills further.

In conclusion this argument agrees with the DoE (2003), Provasnik, Kasteberg, Ferraro, Lemanski, Roey, Jenkins (2012); TIMSS \& PIRLS International Study Center(2009),accentuating that in the teaching of problem solving; the reasoning skills such as analysing, selecting, synthesising, generalizing and conjecturing are important skills for learners to have, but also important life-skill survival. The empirical evidence; SACMEQ Report by Moloi \& Chetty (2011); Su, Choi, Lee, Choi, McAninch (2013) quoted Baroody et al (2004) evinced that the wealth of marginalised knowledge learners possessed enabled them to unearth and relate the mathematical content and skills addressed by the CAPS documents. Mathematical content areas such as shape; space and measurement, algebra, probability concept( they ways of placing the token cow on the board and chances of winning the board game shows the understanding of probability).

\section{Acknowledgement}

This work is based on the research supported in part by the National Research Foundation of South Africa (UNIQUE GRANT NO: 89673).

\section{References}

Anthony, G \& Walshaw, W. (2009). Characteristics of effective teaching of maths: A view from the west. Journal of Mathematics Education, 2(2),147-164.

Campbell, J.(2006). Theorising Habits of Mind as a framework for Learning. In Paper presented at the AARE Annual Conference Adelaide 2006.

Chilisa, B., Ntseane, G. (2010). Resisting Dominant Discourses: Implications of Indigenous, African Feminist Theory and Methods for Gender and Education Research. Gender and Education, 22(6),617 -632.

Chilisa, B. (2012). Indigenous Research Methodologies. USA:SAGE Publications.

De Corte, E. (2000). High-powered learning communities: A European Perspective. A keynote address presented to the first conference of the Economic and Social Research Council's Research programme on Teaching and Learning. Lecester, England. 
Department of Basic Education. (2011). Mathematics: Curriculum and assessment Policy statement Grades 10-12.Pretoria: Department of Basic Education.

Department of Education. (2003). National Curriculum Statement Grades 10-12(General): Mathematics. Pretoria: Department of Education

Eruera, M. (2010). Ma Te Whānau Te Huarahi Motuhake:Whānau Participatory Action Research groups MAI Review, 3

Graven, M. \& Schafer, M .(2013). Interview with a mathematics Doodler - Dr Sizwe Mabizela, Deputy Vice Chancellor, Rhodes University. In Bizony,M. \& Tshabalala, L.(Eds.). Grahamstown: Amesa,Learning \& Teaching Mathematics:

Graven, M. (2003). Learning as Changing Meaning, Practice, Community, Identity and Confidence: The Story of Ivan. For the Learning of Mathematics. 23(2),28-36.

Grinstein, L.S \& Lipsay, S.L. (2001). Encyclopedia of Mathematics Education. New York: Routledge.

Hamalainen,R., Manninen,T.\& Jarvelas,S.(2006). Learning Collaborate: Designing Collaborative in 3-D games Environment. Academic Journal of International and Higher Education, 9(1),47-61.

Haylock, D. (2010). Mathematics Explained for Primary Teachers, $4^{\text {th }}$ edition. California: SAGE Publications.

Jorgensen, R. \& Lowrie, T. (2013). Both ways strong: Using digital games to engage Aboriginal Learners. International Journal of Inclusive education,17(2),130-142.

Leornard, J. (2008). Culturally Specific Pedagogy in the Mathematics Classroom: Strategies for Teachers and Students. Routledge Taylor \& Francis Group

Lynn, M. (2004). Inserting the "Race" into Critical Pedagogy: An Analysis of race-based espistemologies. Educational Philosophy of Theory, 36(2),153-164

Lynn, M. 2006. Race, Culture and the Education of Americans. Educational theory, 56(1),107-119.

Mahlomaholo, M.G .(2012). Social communication towards sustainable Physical Science learning environments. Journal for Community Communication and Information Impact (special Edition), 17,3 - 20.

Maskene, I. (2011). The free attitude interviews in context. Research for the future. (Unpublished Paper)

McGregor, S.L.T., \& Murnane, J. A. (2010). Paradigm, Methodology and method: Intellectual integrity in consumer scholarship. International Consumer Studies, 34(4), 419-427.

Moloi, M.Q \& Chetty, M. (2011). Southern and Eastern Africa Consortium for Monitoring Educational Quality. Trends in achievement levels of grade 6 pupils in South Africa. Policy brief, 1, 1-7

Muijs, D., \& Reynolds, A. 2(011). Effective Teaching Evidence and Practice. California: SAGE Publishers Ltd.

Provasnik, K., Kastberg, D., Ferraro, D., Lemanski, N., Roey, S., \& Jenkins, F. (2012). Highlights from TIMSS 2011: Mathematics and Science Aclueremot of US. Fourth \& eighth grade students in an internal context (NCES 2013-009). Natural Centre for Education Statistics. Institute of Education (US). Department of Education, Washington D.C

Stinson, D.W \& Bullock, E.C. (2012). Critical Postmodern Theory in Mathematics Education Research: A praxis of uncertainty. Educational Studies, 80,41-55.

Su, Yu-Law, Choi, K.V., Lee, W.C., Choi, T. \& McAninch, M. (2013). Hierarchical cognitive diagnostic analysis for TIMSS 2003 mathematics. Centre for Advanced Studies in Measurement and Assessment, 35,1-71

Van De Walle, J.A., Karp, K.S., \& Bay- Williams, J.M. (2010). Elementary \& Middle school Mathematics: Teaching Developmentally. Pearson Education, Inc., US

Yosso, T J. (2002). 'Toward a Critical Race Curriculum'. Equity\& Excellence in Education, 35:2, 93 - 107.

Yosso, T J. (2005). Whose Culture has Capital? A Capital race Theory discussion of community cultural wealth. Race ethnicity and Education 8(1),69-91. 